\title{
POLÍTICAS EDUCACIONAIS BRASILEIRAS, INTEGRAÇÃO LATINO- AMERICANA E O MERCOSUL EDUCACIONAL: QUESTÕES PARA DEBATE
}

\author{
Oséias Santos de Oliveira ${ }^{1}$ \\ Universidade Federal de Santa Maria - UFSM/RS - PPGE
}

\section{RESUMO}

O presente artigo tem como escopo a discussão das atuais políticas educacionais brasileiras e as ações educacionais propostas para o Mercosul - Mercado Comum do Sul que são delimitadas através da legislação, dos programas e planos governamentais executados na perspectiva de aproximar interesses e intenções que se pautam por definições oriundas das macro políticas internacionais, orientadas pelo Banco Mundial, ONU, UNESCO, UNICEF, FMI e outros órgãos articulados aos interesses dos países centrais e a serviço do capital. Claramente se visualiza a interferência destes organismos internacionais na organização dos sistemas de ensino em especial de países em desenvolvimento, como o Brasil e demais países da América Latina. O processo de globalização, articulado às políticas neoliberais, propõe a formação de blocos econômicos, com vistas ao desenvolvimento do sistema capitalista. O Mercosul, surge, neste contexto, articulando políticas econômicas com a proposição de integrar os países latino-americanos. Assim, a presente análise qualitativa, de caráter bibliográfico, explora as políticas educacionais brasileiras e o fortalecimento do Mercosul Educacional, com destaque ao papel da Universidade no processo de democratização do Mercosul.

Palavras-chave: Políticas Educacionais brasileiras; Mercosul; Mercosul Educacional;

Integração Latino-americana.

\section{EDUCATIONAL POLICIES BRAZILIAN, LATIN AMERICAN INTEGRATION AND MERCOSUR EDUCATION: ISSUES FOR DISCUSSION}

\begin{abstract}
This article has the objective of the discussion of the current Brazilian educational policies and educational activities proposed for the Mercosur - Southern Common Market that are defined through legislation, programs and government plans implemented with a view to bringing the interests and intentions that are governed by macro definitions derived from international policies, guided by the World Bank, ONU, UNESCO, UNICEF, FMI and other bodies articulate the interests of core countries and the service of capital. Clearly viewing the interference of international organizations in the organization of education especially in developing countries like Brazil and other Latin American countries. The process of globalization, combined with neoliberal policies, proposes the formation of economic blocs, with a view to the development of the capitalist system. Mercosur, appears in this context, linking economic policies and the proposal to integrate the Latin American countries. Thus, this qualitative analysis of bibliographical character, explores the Brazilian educational policies and the strengthening of Mercosur Education, with emphasis on the role of the University in the democratization process of Mercosur.

Keywords: Education Policy in Brazil, Mercosur; Mercosur Education, Latin American Integration.
\end{abstract}




\section{Introdução}

As políticas educacionais brasileiras no tempo presente são reflexos de acordos, intenções e ações das políticas internacionais. O Brasil, enquanto signatário dos projetos educacionais em âmbito macro, busca promover a educação com intuito de elevar os índices educacionais atuais que ainda mostram-se precários em muitos aspectos. Neste sentido, a legislação brasileira vem sendo discutida e construída com vistas a promover a qualidade do ensino e de dar as condições para que este processo aconteça. Temos, na Constituição Federal de 1998, na Lei de Diretrizes e Bases da Educação Nacional - LDB n 9.394/96, no Plano Nacional de Educação/2001, estabelecidas as principais diretrizes e metas a serem orientadoras das políticas educacionais. Recentemente, a instituição do PDE - Plano de Desenvolvimento da Educação/2007 vem corroborar com a ideia de uma educação de qualidade que necessariamente precisa ser pensada e assumida não apenas pelas esferas administrativas e governamentais, mas por toda a sociedade que deseja livrarse das amarras do subdesenvolvimento e atraso educacional.

$\mathrm{O}$ atual contexto político fortemente influenciado pela economia globalizada que, em nome da articulação provoca ações nas diferentes áreas das políticas públicas e sociais, tem, na formação de blocos econômicos uma das principais estratégias para que as nações possam vencer desafios, superar seus problemas e desenvolver-se plenamente. O Mercado Comum do Sul - Mercosul, é criado em 1991 com o propósito de fomentar o desenvolvimento econômico e a integração entre os países que integram este bloco.

A discussão da realidade educacional brasileira e dos demais países que compõe o Mercosul tem sido pauta constante nas reuniões promovidas pelos governos da América Latina. A preocupação com o desenvolvimento da educação associada ao crescimento econômico projeta o Mercosul Educacional que tem como marco a assinatura do Plano Trienal para o Setor Educação (1992) cujos objetivos centram-se na formação de uma consciência social favorável ao processo de integração; na capacitação de recursos humanos para contribuir ao desenvolvimento econômico e na compatibilização e a harmonização dos sistemas educativos.

Debater as atuais políticas educacionais brasileiras na perspectiva da integração latino-americana, com o fortalecimento do Mercosul torna-se prioridade no atual contexto da globalização. A investigação proposta neste trabalho de cunho qualitativo se baseia em uma abordagem bibliográfica que busca, no referencial disponível na legislação e em análises de Gadotti (2007, 2008), Lampert (1998), Vidal (1999), Raizer (2007), Grandi (1999), Barbiero e Chaloult (2003), Costa (2008) entre outros traçar um perfil da educação e os desafios e perspectivas frente ao Mercosul.

\section{O cenário internacional e as orientações gerais das políticas educacionais}

As orientações que emanam dos organismos internacionais e dos documentos que se originam a partir das conferências mundiais são decisivas para a consecução e execução das políticas educacionais dos países em desenvolvimento. Percebe-se nitidamente as interferências de organismos internacionais, delimitando caminhos a serem trilhados pelos Sistemas de Ensino, escolas e sujeitos envolvidos no processo educativo - claramente expostos nos desejos e intenções que emanam através das Conferências Internacionais, que têm, sob respaldo e patrocínio da ONU - Organização das Nações Unidas, da UNESCO Organização das Nações Unidas para a Educação, a Ciência e a Cultura, do FMI - Fundo Monetário Internacional e do BM - Banco Mundial, fomentado discussões e políticas 
educacionais, em especial nos países em desenvolvimento, como o Brasil e demais países da América Latina.

O ano de 1990 é assinalado como o marco das grandes discussões educacionais, quando as nações, representadas pelos seus governos reunem-se na Tailândia para firmarem um pacto pela Educação para Todos, fixando metas que são expostas no documento conhecido como Declaração de Jontiem e que darão suporte para o planejamento da educação em cada país signatário desta carta de intenções. Logo a seguir, no ano de 1993, na Índia, os nove países com a maior população mundial, dentre eles Brasil, Egito, Índia e outros, reúnem-se para discutir as metas definidas no início da década na Tailândia. A Declaração de Nova Delhi sobre Educação para Todos, documento originário deste encontro, vem ratificar o compromisso dos países mais populosos do mundo e com os maiores índices de analfabetismo, reprovação, evasão e precariedade dos sistemas educativos, na tentativa de colocar em prática ações que efetivamente sinalizam para um avanço nas condições de ensino, aprendizagem e organização da educação.

A preocupação com a educação inclusiva e com o atendimento das pessoas com necessidades educacionais especiais, com a estrutura dos sistemas de ensino e das escolas, com a formação de professores para atuarem nesta modalidade e com a alocação de recursos financeiros para garantir a inclusão educacional movimenta mais uma Conferência Internacional, desta vez realizada na Espanha, em 1994. Fruto destas discussões a Declaração de Salamanca torna-se documento referência para que as nações pensem a inclusão dentro de uma proposta de Educação Para Todos.

Ainda na efervescência dos grandes debates em torno da educação mundial, organiza-se na Alemanha, no ano de 1997, mais um espaço para análise, diagnóstico da realidade e encaminhamentos, desta vez em relação à educação de adultos. A Declaração de Hamburgo sobre Educação de Adultos sinaliza para a necessidade de, globalmente, articular ações para a alfabetização, inserção no meio escolar e qualificação de jovens e adultos. Em decorrência deste movimento mundial são instaurados cursos supletivos, de certificação, de alfabetização, tanto presenciais quanto a distância, com financiamento público e também de empresas privadas.

No limiar do século XXI, quando completa uma década da Declaração de Jontiem, o mundo volta-se para uma reflexão contundente dos avanços, retrocessos e perspectivas das metas assumidas na Tailândia. $\mathrm{O}$ quadro que se observa não é nada animador, sendo que os indicadores educacionais continuam em situação precária e necessitam de uma reavaliação. Neste sentido, firma-se o Compromisso de Dacar (Senegal), no ano 2000, quando os países reafirmam seu engajamento no cumprimento das metas assumidas na década anterior.

Os ministros de educação da América Latina e Caribe são chamados pela UNESCO a reunir-se na Bolívia em 2001 com a intenção de fomentar a discussão sobre a realidade regional, caracterizada por mais de 220 milhões de pessoas vivendo na pobreza, excluídos do processo de desenvolvimento econômico e afetados pelos altos índices de analfabetismo, de reprovação, evasão, bem como de falta de escolas e de recursos para sua manutenção. A expectativa dos países situados neste espaço geográfico e aproximados pelas desigualdades e necessidades, é de apostar na educação como forma de transformação da realidade desfavorável. Assim, encaminham à UNESCO o documento conhecido como Declaração de Cochabamba , onde expõe suas necessidades e perspectivas e ainda cobram a cooperação internacional no sentido de atenção ao desenvolvimento das tarefas e propostas da Declaração, bem como no fortalecimento do processo decisório e da capacidade de execução nacionais (UNESCO, 2001). 


\section{O contexto educacional brasileiro: ajuste das políticas públicas em sintonia com o projeto neoliberal}

O processo de redemocratização do Brasil nos anos de 1980, após mais de duas décadas de ditadura que é marcada pelo cerceamento das liberdades individuais, do engajamento coletivo e da tentativa de silenciamento dos movimentos sociais e de classe, se consolida com a Constituição Federal de 1988, a chamada Constituição Cidadã. O movimento popular organizado é fator marcante na discussão de propostas para a referida Carta Magna brasileira. Neste sentido a democratização se consolida na escolha direta dos representantes políticos e na participação da sociedade na tomada de decisões e escolhas para o futuro que se antevê cheio de expectativas e possibilidades.

O movimento de reabertura política e o reconhecimento do poder popular vem acompanhado de imposições mundiais, fortemente caracterizadas pela globalização da economia na perspectiva neoliberal. Diante deste cenário mundial que delimita as políticas para os países em desenvolvimento o Brasil é envolvido em reformas em todas as áreas das políticas públicas que têm implicações diretas no modo de planejar e gerir a sociedade, bem como na definição dos objetivos que orientarão a economia, a cultura, o trabalho, a educação e outras áreas importantes para a organização social.

A análise do campo educacional permite a visualização das reformas que, oriundas do processo de globalização, são imposta aos países da América Latina nos anos de 1990. Estas reformas têm seu foco pautado na descentralização da gestão educacional. Frente às delimitações expostas através de acordos, intenções e ações dos organismos internacionais, observa-se um movimento dos países empobrecidos ou daqueles que se encontram em processo de desenvolvimento, no sentido de promover a educação com o intuito de melhorar significativamente a realidade educacional que se apresenta que precária em muitos aspectos.

O Brasil, como signatário destes acordos mundiais, estabelece mecanismos na própria legislação com o intuito de colocar em prática as metas acordadas em âmbito internacional. Com isto objetiva-se promover a qualidade do ensino e de dar as condições para que este processo aconteça. A Constituição Federal de 1998 já reconhece a educação como uma política pública e dá a ela uma atenção especial no sentido de redimensionar seus fins e princípios, estabelecendo obrigatoriedade e progressiva participação da comunidade em sua organização, além de prever a cooperação entre os sistemas de ensino e a participação efetiva da União no sentido de seu financiamento.

A discussão da Lei de Diretrizes e Bases da Educação Nacional - LDB $\mathrm{n}^{\circ}$ 9.394/1996 envolve os movimentos comunitários, de classes, sindicatos e sociedade civil no embate com o poder político para firmar a perspectiva de uma educação que atendesse aos princípios da Constituição Cidadã. No processo de elaboração desta lei acaba prevalecendo, no entanto, a visão política claramente comprometida com os ideários neoliberais, fruto de barganhas político-partidárias e de compromissos privados.

A necessidade de implementar e ajustar o cenário educacional volta ao palco das discussões com a elaboração do Plano Nacional de Educação/2001, onde são estabelecidas as principais diretrizes e metas a serem orientadoras das políticas educacionais. Ainda que as orientações do Plano Nacional de Educação (PNE), confirmadas nos Planos Estaduais e Municipais de Educação tenham uma visão de abrangência de uma década, observa-se uma lentidão em sua execução. Os índices educacionais e a realidade precária da educação pública brasileira denunciam o desinteresse político em efetivar de fato a consolidação do PNE. 
Recentemente, a instituição do PDE - Plano de Desenvolvimento da Educação/2007 vem corroborar com a ideia de uma educação de qualidade que necessariamente precisa ser pensada e assumida não apenas pelas esferas administrativas e governamentais, mas por toda a sociedade que deseja livrar-se das amarras do subdesenvolvimento e atraso educacional.

O Decreto $\mathrm{n}^{\circ}$ 6.094, de 24 de abril de 2007 dispõe sobre a implementação do Plano de Metas Compromisso Todos pela Educação, pela União Federal, em regime de colaboração com Municípios, Distrito Federal e Estados, e a participação das famílias e da comunidade, mediante programas e ações de assistência técnica e financeira, visando a mobilização social pela melhoria da qualidade da educação básica. Ao todo são fixadas 28 diretrizes no Plano de Metas Compromisso Todos pela Educação que abordam questões pontuais que envolvem diferentes áreas e buscam ampliar a jornada escolar, reduzir repetência e evasão, incluir pessoas com necessidades especiais, valorizar os professores e envolvê-los nas discussões das propostas pedagógicas das escolas, promover a educação infantil e educação de jovens e adultos, propiciar a avaliação educacional através do IBEB - Índice de Desenvolvimento da Educação Básica com planejamento de ações voltadas às realidades mais precárias, além de integração entre os programas da área da educação com os de outras áreas como saúde, esporte, assistência social, cultura, dentre outras ações (BRASIL, 2007).

Gadotti (2008. p. 24 - 26) ao discutir o PDE, afirma que este plano estabelece como foco a aprendizagem, e busca alcançar resultados concretos, promovendo a gestão participativa na rede de ensino e nas escolas. Neste sentido, o plano pode dar certo onde outros falharam, pois não é tecnocrático e mirabolante - é um plano simples e objetivo que visa a qualidade da educação.

\section{O Mercado Comum do Sul e as políticas de integração: a perspectiva do Mercosul Educacional}

O atual contexto político fortemente influenciado pela economia globalizada que, em nome da articulação provoca ações nas diferentes áreas das políticas públicas e sociais, tem, na formação de blocos econômicos uma das principais estratégias para que as nações possam vencer desafios, superar seus problemas e desenvolver-se plenamente.

A perspectiva de aparelhamento do sistema capitalista com vistas a sua manutenção e ampliação se consolida na macro-organização econômica e política que, na visão de Costa (2008) corresponde a um:

movimento estrutural no sentido de absorver positivamente todas as mudanças profundas que estão ocorrendo no interior do sistema capitalista em função da globalização. Com esta macro-organização, o grande capital busca unificar novamente sua estratégia, agora num patamar superior, a partir dos blocos econômicos sem, no entanto, abolir a concorrência entre os próprios capitais. Neste sentido, a formação desses blocos funcionaria como espaços supranacionais de acumulação, a partir dos quais poderia se desenvolver o processo de concorrência no ambiente novo da globalização (COSTA, 2008, p. 182).

Deste modo, os chamados megablocos possibilitariam a gerência dos países centrais em situações de dependência recíproca entre os blocos envolvidos nesta formatação. De outro lado, a estrutura em megablocos torna ainda viável a hierarquização 
das ações políticas, bem como das preferências comerciais, vantagens comparativas e reciprocidades que se articulam entre as nações de cada área econômica. Toda organização que se firma no sentido de aproximação de blocos econômicos e nações visa, em um patamar superior, a regulação macroeconômica (COSTA, 2008).

O Mercado Comum do Sul - Mercosul, formado pelo Brasil , Argentina, Uruguai e Paraguai surge em 1991, através do Tratado de Assunção. Em sua atual configuração o Mercosul conta ainda com a Venezuela que constitui-se em um Estado Parte, pois encontra-se em tramitação o Protocolo de Adesão deste país ao bloco econômico. Os Estados Associados que são Bolívia, Chile, Colômbia, Equador e Peru integram-se ao Mercosul com forte compromisso do bloco econômico em aproximar-se destas nações de modo a aprofundar o processo de integração regional.

Lampert ao discutir a perspectiva do Mercosul, sua configuração e intenções que o caracterizam, destaca que o Mercado Comum do Sul:

\begin{abstract}
é uma tentativa de países da América do Sul de se organizarem, após os longos anos de ditadura militar, para enfrentar conjuntamente as constantes crises políticas, econômicas e sociais que afetam a vida do cidadão sul-americano. Sabe-se de antemão que esse projeto da moderna burguesia nacional e internacional tem como centro o capital e não inclui os marginalizados e trabalhadores, a grande maioria da população desses países. As discussões e decisões ocorrem em esferas nas quais o povo não participa nem emite opiniões. Tem simplesmente a incumbência de cumprir as tarefas estabelecidas (LAMPERT, 1998, p. 2).
\end{abstract}

De modo amplo, o Mercosul, desde sua formação, passou a ter um significado muito expressivo para os quatro países que o compõe, "posto que desenvolveu de maneira acentuada um processo de complementariedade das quatro economias e melhorou bastante o comércio bilateral" (COSTA, 2008, p. 187). Apesar dos muitos problemas que hoje ainda se verifica, fruto de profundas crises econômicas que envolvem os países membros, a aposta na integração regional tem sido positiva, quando os demais países latino-americanos vislumbram no Mercado Comum do Sul como a saída para a aproximação e fortalecimento conjunto.

A perspectiva de ação política e decisória que sustenta o Mercosul se configura, inicialmente, em torno de instâncias governamentais, quando nestes círculos fechados eram definidas as metas, propostas e acordos para criação, implementação e desenvolvimento deste bloco econômico. Contudo, muito lentamente se observa uma maior abertura de espaços para discussão com a sociedade civil, com os parlamentos, partidos políticos, organismos ligados ao meio empresarial e sindical, além de universidades e órgãos-não governamentais, onde se articulam os diferentes sujeitos e expressões da sociedade civil. Isto posto, concorda-se com a posição de Grandi (1999) quando este autor expõe, com forte expressão crítica, a existência de um real déficit democrático e social no processo de construção do Mercosul.

Por sua vez, Barbiero e Chaloult (2003) percebem, face à crítica da não democratização do Mercosul, que existe uma consciência pública regional em formação. A partir desta inserção da sociedade civil algumas alterações no projeto original já foram possíveis, com a criação de canais consultivos, institucionalmente estabelecidos, o que evidencia de fato esta maior integração com o locus social e, de modo muito particular, afetam as relações de poder em jogo na arena do espaço público.

No sentido de promover ações conjuntas para o desenvolvimento da educação nos países que compõe o bloco, surge o Mercosul Educacional que atende por Setor 
Educacional do Mercosul (SEM), sendo este integrado pelos ministros de educação dos países membros e visa a discussão e implementação de uma agenda de integração regional.

Conforme apresentam Beshara e Pinheiro, as metas definidas pelo Setor Educacional do Mercosul, em termos específicos:

são esmiuçadas e divulgadas periodicamente por meio de "planos de ação", que informam as estratégias, os princípios e os resultados esperados pelo acordo, além de avaliar os projetos concluídos ou em processo de execução. O primeiro plano de ação foi anunciado logo após o Protocolo de Intenções de 1991; três anos depois, em Ouro Preto, estabeleceu-se outro plano, que duraria de 1994 a 1997. Em 1998, entrou em vigor novo plano, substituído pelo plano de ação 2001-2005. Finalmente, em 2006 foi lançado novo documento com as diretrizes atuais, que devem durar até 2010 (BESHARA E PINHEIRO, 2008, p. 4).

As definições a acordos constantes nos Planos de Ação orientam as políticas de integração para o Mercosul, focalizando como objetivo a efetiva contribuição para a integração regional a partir de acordos e execução de políticas educativas que estejam articuladas com um projeto de cidadania regional que necessariamente precisa ser pensada com base em aspectos prioritários e urgentes, definido no Plano de Ação 2006-2010 como "una cultura de paz y el respeto a la democracia, a los derechos humanos y al medio ambiente" (PLAN DEL SECTOR EDUCATIVO DEL MERCOSUR - 2006 - 2010, 2006, p. 10).

Percebe-se que o Plano de Ação 2006-2010, reafirma as intenções propostas quando da articulação inicial, já expressa no Tratado de Assunção, quando da construção do Mercosul, pois ao destacar o foco de atuação para ampliar a perspectiva de integração declara que:

En todos los países signatarios del Tratado de Asunción, se percibió com claridad que la educación debía jugar un rol principal y que El MERCOSUR no podía quedar supeditado a meros entendimientos econômicos (PLAN DEL SECTOR EDUCATIVO DEL MERCOSUR - 2006 - 2010, 2006, p.4).

Conforme indicadores do Mercosul Educacional (2006), em relação ao Ensino Superior, contata-se uma pequena elevação nos índices de expansão deste nível de ensino nos países membros do Mercosul, sendo que o destaque positivo neste cenário fica por conta do Paraguai com uma variação positiva de quase 12 pontos percentuais, seguido pela Argentina(11,6\%), Brasil(5,3\%), Bolívia(4,5\%) e Chile $(4,1 \%)$. Esta variação pode ser exposta na Fig 01: 
Gráfico 01: Variação de acesso ao Ensino Superior (1999-2003) segundo dados da UNESCO.

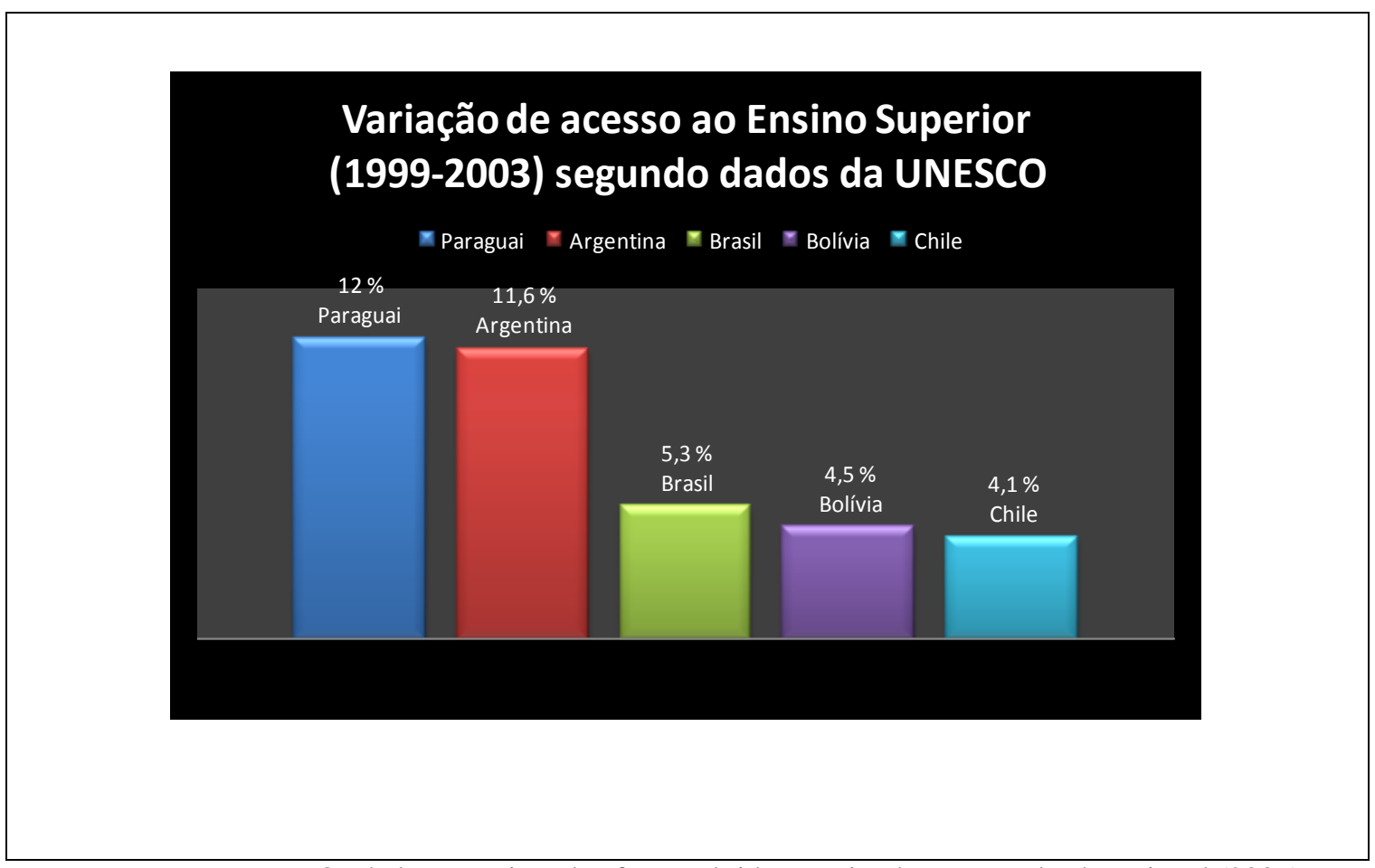

Fonte: Os dados mencionados foram obtidos no site do Mercosul Educacional (2006). http://mercosul.mec.gov.br/asp/Estatistica/sistemas.asp

Raizer, ao discutir estas questões de desnivelamento e entre as nações integrantes deste bloco, considera que deverá ser grande o esforço dos países membros do Mercosul para que de fato problemas como as grandes disparidades educacionais atualmente vigentes possam ser solucionadas, até que alcancemos a totalidade de acesso aos níveis superiores de ensino e mesmo em nível médio. A posição do autor é destacada quando afirma que:

mesmo que a elevação dessas taxas persistisse, os países latinoamericanos demorariam cerca de 120 anos para atingir taxas médias de acesso de $100 \%$, no ensino superior e, cerca de 80 anos, para atingir essas taxas no ensino médio (RAIZER, 2007, p. 162).

Assim, é prioritário que esteja na pauta de debates uma educação descentralizada, a partir da qual a integração da América Latina já está dando seus primeiros contornos. Considerando que a educação e a cultura têm representado historicamente apenas um apêndice nos mercados nacionais e estrangeiro, Gadotti (2007) defende que "a educação deverá ser um dos eixos fundamentais da transformação da economia e do perfil produtivo da nossa região diante das atuais circunstâncias e desafios".

Em se tratando do Mercosul, a pauta de discussões priorizou, desde o início a educação sendo criado em 1992. Gadotti (2007, p. 11), em documento produzido em encontro entre países do Mercosul, assinala que a primeira programação desse setor foi criação do Plan Trienal para la Educación en el Mercosur. Destaca ainda que este Plano prevê o papel estratégico desempenhado pela educação no processo de integração, para alcançar o desenvolvimento econômico, social, científico-tecnológico e cultural da região 
além de estabelecer os mecanismos necessários para viabilizar o sistema comum de reconhecimento e equivalência dos estudos primários e médios, cursados em qualquer dos quatro países.

Entre as metas do Plano Trienal destaca-se ainda a preocupação em incrementar o intercâmbio acadêmico- técnico-científico, em nível de ensino superior, possibilitando uma maior mobilidade de docentes, alunos, pesquisadores e técnicos. Deste modo verifica-se que a preocupação com o desenvolvimento da educação associada ao crescimento econômico projeta o Mercosul Educacional a uma posição de destaque no enfoque educativo do bloco econômico.

O Plano Trienal para o Setor Educação objetiva a formação de uma consciência social favorável ao processo de integração; a capacitação de recursos humanos para contribuir ao desenvolvimento econômico e a compatibilização e a harmonização dos sistemas educativos. Estes três objetivos devem ser perseguidos por todos os países membro do Mercosul que, visando alcançar sucesso em seus propósitos devem propor e executar ações práticas de aproximação e de integração. A consecução da integração entre as nações integrantes dependerá em muito da articulação política, econômica, cultural que em um contexto mais amplo englobará também as políticas educacionais.

Um processo de integração que se limite apenas aos aspectos econômicos, desconsiderando os demais eixos da integração provavelmente não alcançará sucesso em sua proposta. A integração depende muito mais de relações que se estabelecem no cotidiano das nações, com enfrentamento conjunto de seus dilemas e busca também coletiva de soluções para problemas comuns, como o caso das disparidades educacionais, hoje contatadas na América Latina.

O Setor Educacional do Mercosul tem, neste contexto, papel decisivo para o desenvolvimento das políticas em diferentes níveis, seja entre os países que constituem o este mercado econômico, entre as distintas instâncias que o compõe, entre as relações do setor educativo com os demais setores sociais e econômicos, entre os diferentes âmbitos da sociedade e atores educacionais, em cada país ou vinculados a outras regiões ou países (PLAN DEL SECTOR EDUCATIVO DEL MERCOSUR - 2006 - 2010, 2006).

Deste modo, cabe destacar a missão do Mercosul Educacional assumida na elaboração do Plano do Setor Educativo do Mercosul, que assim é definida:

Conformar un espacio educativo común, a través de la concertación de políticas que articulen la educación con el proceso de integración del MERCOSUR, estimulando la movilidad, el intercambio y la formación de una identidad y ciudadanía regional, con el objeto de lograr una educación de calidad para todos, con atención especial a los sectores más vulnerables en un proceso de desarrollo con justicia social y respeto a la diversidad cultural de los pueblos de la región (PLAN DEL SECTOR EDUCATIVO DEL MERCOSUR - 2006 - 2010, 2006, p. 9).

O olhar sobre os dados demográficos e educacionais de países como Argentina, Brasil, Chile, Paraguai e Uruguai revela a disparidade entre o contingente populacional e a realidade de seus sistemas de ensino. Com base nestas diferentes situações o Mercosul Educacional se insere de modo a propiciar a efetiva integração. A Fig. 02 revela estes dados: 
Fig 02: Características demográficas e educacionais de países membros do Mercosul

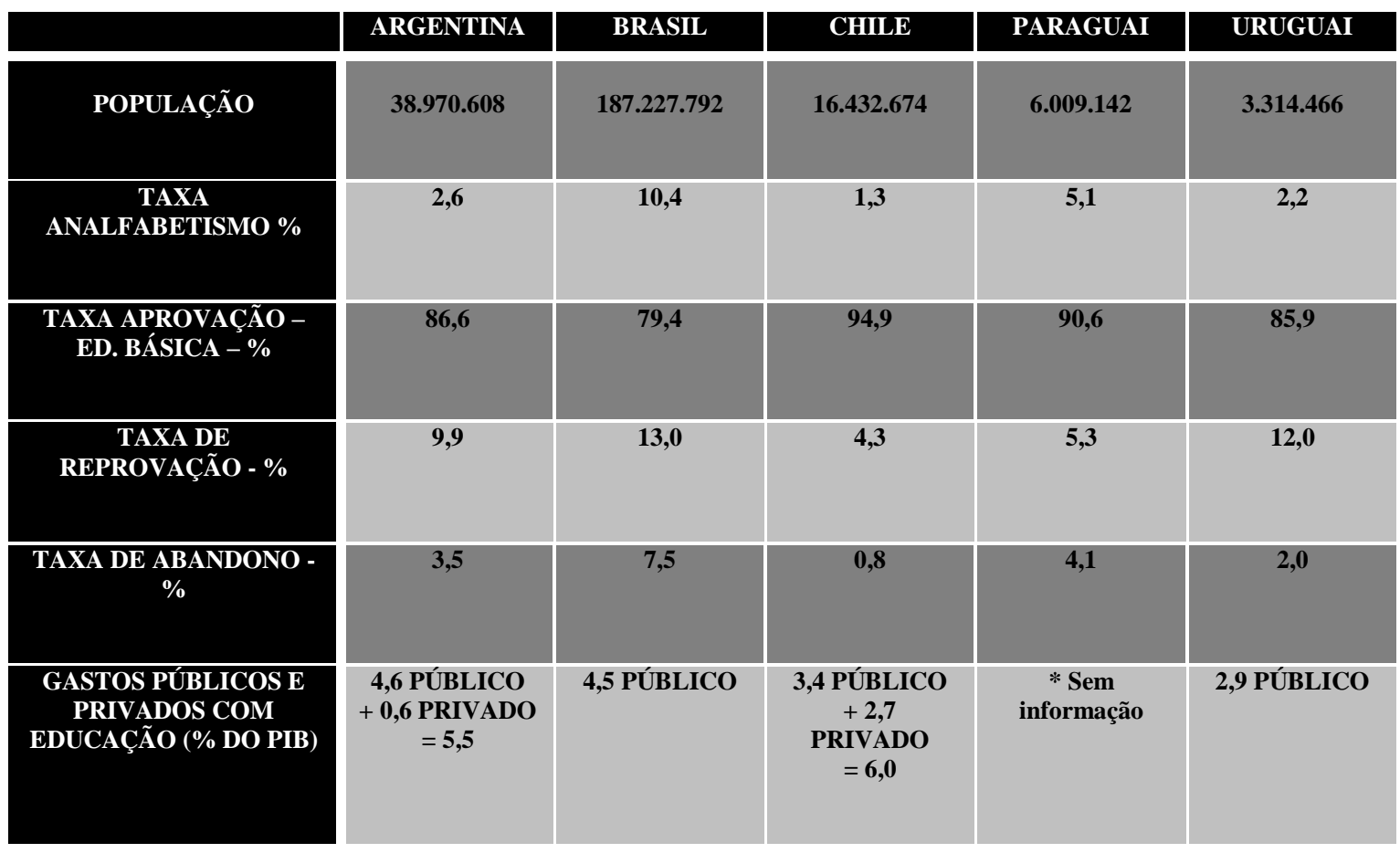

Fonte: Os dados mencionados foram obtidos no site do Mercosul Educacional (2006) http://mercosul.mec.gov.br/asp/Estatistica/sistemas.asp

São muitos e diferentes os desafios para o Mercosul Educacional de modo promover a integração. Estes desafios vão desde a concepção de educação e de integração até medidas práticas. Assim, busca-se de promover uma integração num sentido mais amplo do que o da lógica delimitada pelo mercado, e que se insere na pauta de uma concepção de educação emancipadora. A integração não pode limitar-se ao mercado econômico; ela deve estar articulada com os aspectos socioeducacionais e culturais que poderão realizar o sonho da "Pátria Grande". (GADOTTI, 2007, p. 33). Este sonho simboliza uma Pátria grande, latino-americana, como idealizou Simón Bolívar durante o processo de independência de vários países. Pátria grande significa também uma independência econômica dos países da região com relação aos demais países centrais em uma verdadeira integração regional latino-americana que extrapola o econômico e promove a integração das nações em todos os aspectos sociais e culturais.

Entretanto, ainda que a integração seja um sonho, é preciso considerar o que discute Vidal quando afirma que:

Embora o sentir panamericanista corra pelas veias de muitos, ele não é um fundamento suficiente para a adesão ao integracionismo. Esta causa precisa de motivos (razões) fortes, que a justifiquem e lhe sirvam de norte, já que a conciliação de interesses díspares na busca de um "bem comum" tem sempre um preço. A presença de uma meta mais elevada que todas as partes aceitem como benéfica e sua é fundamental. Neste caso, a construção de uma ordem social baseada na dignidade humana, em que a liberdade e a justiça sejam igualmente respeitadas, em que os direitos humanos fundamentais, bem como os respectivos deveres, resguardem verdadeiramente a cidadania - entre outras coisas - pode servir como meta-guia, pois é um sonho antigo e sempre novo, que o 
coração sensível do latino-americano acalenta para si e para os seus iguais. Perseguir e realizar esse sonho é um desafio que o presente nos propõe. Creio que a América Latina tem uma suficiente reserva de valores no sentido de se tornar referência e esperança para a humanidade, no que tange a qualidade de vida (VIDAL, 1999, p. 49).

A criação de uma agenda para o Mercosul Educacional, na visão de Gadotti (2007) seria a efetivação prática que ainda falta para o alcance dos objetivos de integração e desenvolvimento. Nesta agenda, necessariamente deveriam estar incluídas questões como a criação de uma proposta de conteúdos mínimos para a história e a geografia da integração regional para serem adotados pelos países do Mercosul com enfoque voltado para a produção de materiais didáticos e formação de professores para atuarem com qualidade no ensino; as escolas precisam conhecer mais sobre o Mercosul e os intercâmbios entre estudantes, professores e pesquisadores devem ser realizados entre os países membros de modo a fortalecer as trocas de experiências educativas; o Mercosul precisa ainda ser democratizado, sendo que todas as pessoas devem conhecer e ter consciência da necessidade de fortalecer os laços de integração para o a melhora da condição de vida nos países membros do Mercosul; a criação de grupos de estudo e de pesquisa sobre a educação nos diferentes países do Mercosul, a criação e consolidação de redes por temas educacionais; um banco de dados sobre experiências inovadoras da região e especialmente a formação de recursos humanos voltados para as questões da educação do Mercosul, capacitados para formar formadores em educação para a integração.

Para Stallivieri (s.d, p. 11) a tarefa do poder público e das instituições de Ensino Superior se consolida na união de esforços no sentido de estabelecer estratégias em comum para o desenvolvimento de ações de integração que projetarão o Mercosul, não somente como uma potência econômica, mas também como um polo gerador e exportador de cultura própria, não esquecendo-se de seu potencial natural e da característica cultural marcante de seu povo, que deseja não ser mais colonizado. Não esquecendo, no entanto o papel destacado das universidades privadas que, com o engajamento na pesquisa e nos projetos de extensão e ensino buscam consolidar propostas de integração seja nos campos científicos, humanos e culturais.

\section{O Plano do Setor Educacional do Mercosul 2011-2015: uma agenda em construção}

Recentemente a 39 $9^{\mathrm{a}}$ Reunião de Ministros da Educação do Mercosul, realizada em 26 de novembro de 2010, no Rio de Janeiro, foi um momento decisivo de avaliação e de encaminhamentos para os rumos do Mercosul Educacional. Presentes neste conclave os representantes do Brasil, da Argentina, do Paraguai, do Uruguai, do Chile, da Colômbia, do Equador, da Bolívia e do Peru reafirmaram a importância das ações que já vem sendo executado no sentido de promover a integração da América Latina pelo viés da educação.

Conforme consta na Ata $n^{\circ}$ 02/2010 da reunião de Ministros de Educação do Mercosul, a pauta principal de discussões girou em torno da temática: $O$ futuro da integração educacional do MERCOSUL - perspectivas para os próximos cinco anos. Este debate sinaliza a percepção dos representantes dos países integrantes deste bloco econômico no sentido de constatar os avanços já impetrados e projetar uma evolução maior em termos de cooperação na área educacional.

Dentre os temas discutidos na referida reunião, com vista a inclusão no Plano do Setor Educacional do Mercosul (SEM) 2011-2015 salienta-se "o fortalecimento do projeto 
escolas de fronteira, estudo de um mecanismo de reconhecimento de títulos de universidades de excelência da região, educação especial, a valorização do magistério" (MERCOSUL/RME/ATA N ${ }^{\circ}$ 02/10). Dentre as muitas discussões levadas a efeito nesta reunião, também foi assinado um acordo com a União Europeia para a criação de um programa de mobilidade do Mercosul e outro de formação de professores. A inclusão destes temas na pauta de discussões do SEM aponta para a perspectiva de consolidação de projetos que já iniciaram em períodos anteriores e que precisam ser aprimorados e consolidados. A exemplo disto, cita-se o trabalho de intercâmbio docente entre os países do Mercosul, com possibilidade de formação e troca de experiências docentes, através de bolsas que permitem a aproximação entre professores de língua espanhola e de língua portuguesa.

Com vistas a implementação de um plano articulado entre as nações latinoamericanas, a reunião de ministros aprova, entre outros projetos, o Programa de Associação para o Fortalecimento da Pós-Graduação, bem como o Programa de Bolsas de Doutorado para Docentes Mercosul, além do Programa Projetos Conjuntos de Pesquisas. Tais programas vinculam-se em linhas gerais à expansão do ensino, da pesquisa e da extensão e objetivam a aproximação das universidades, alunos e docentes dos países da América Latina.

Nesta última reunião entre os Ministros de Educação do Mercosul também foi apresentado um balanço do plano estratégico do setor educacional do bloco, em vigor nos últimos cinco anos. A avaliação mostrou-se positiva, em especial quando avança no sentido de firmar o chamado Fundo de Financiamento do Setor Educacional do Mercosul (FEM) que constitui-se no primeiro fundo setorial de financiamento de todo o bloco. Cabe ressaltar que até o momento todas as ações desenvolvidas no Mercosul, no campo educacional, eram financiadas pelos respectivos países que as propunham ou pelos organismos internacionais. Convém ressaltar que a partir da implementação deste fundo, prevista para 2011, espera-se promover ações e projetos que denotem continuidade, sem que sejam prejudicados pela rotatividade entre governos e, ainda esta ação de financiamento também visa diminuir as assimetrias entre as realidades educacionais dos países integrantes do Mercosul.

O Mercosul Educacional vem se consolidando como um projeto de integração e sua proposta já vem dando sinais de que isto é possível. Contudo observa-se a necessidade de desenvolver sistemas educacionais mais equitativos entre os países membros, partes e associados. As disparidades educacionais, no que tange ao financiamento, acesso, permanência, valorização de educadores e investimentos em áreas relacionadas ao desenvolvimento educacional precisam ser tema prioritário nas agendas políticas, nos debates locais e regionais e em especial necessitam de ajustes no sentido de estar imbricadas em uma estratégia de desenvolvimento que não se esgota com aproximação de diferentes contextos e culturas, mas que se fortalece na medida em que se articula, se expande e se consolida como projeto em construção. Deste modo, os constantes diálogos entre a sociedade civil organizada e os governos, aliados a uma interação com outros blocos e organismos internacionais, na tentativa de firmar um projeto regional, com reconhecimento no cenário global, se constituem em possibilidades ao desenvolvimento do Mercosul. 


\section{Considerações finais}

A análise das atuais políticas educacionais brasileiras e a proposta de integração latino-americana configurada no Mercosul, e no contexto deste bloco econômico a inserção do Mercosul Educacional, é condição para que avancemos na consolidação do sonho da "Pátria Grande", que tem, na visão de Bolívar os contornos para que a América Latina de fato conquiste sua independência, não apenas política, mas econômica, cultural e educacional e se desenvolva plenamente. Portanto, o projeto de integração que estamos vivenciando atualmente não é algo novo, pois desde muito tempo foi pensado e somente agora as condições para que isto aconteça começam a ser discutidas e executadas.

Ao constatarmos as disparidades entre os sistemas educacionais dos países integrantes do Mercosul, seja em relação a Educação Básica, ou de forma mais contundente no Ensino Superior, percebemos que todas as ações até o momento executadas no sentido da integração educacional ainda situam-se como incipiente e carecem de maior atenção para atingir os objetivos.

Concordamos com o dizer de Lampert (1998) de que é imprescindível considerar que o Mercosul é uma realidade desafiante e os aspectos favoráveis e desfavoráveis de sua implementação estão presentes no processo, então, há necessidade de rever, construir e/ou reconstruir caminhos. O papel das universidades públicas e também das privadas, comumente engajadas nos problemas políticos, econômicos, sociais e culturais, será de suma importância neste processo de integração. O Mercosul poderá se consolidar como um projeto de integração na medida em que a educação se constitui como o viés por onde perpassam todas as demais políticas, sejam de cunho econômico ou social.

\section{Referências}

BARBIERO, Alan e CHALOUlt, Yves. Poder e déficit democrático do Mercosul: estado, centrais sindicais e sociedade civil. Porto Alegre: EDIPUCRS, 2003.

BESHARA, Gregory e PINHEIRO, Letícia. Educação e política externa: a experiência brasileira no Mercosul Educacional. In: Relatório de Pesquisa "Política Externa e Educação - um estudo comparativo sobre a atuação do Brasil na CPLP e no Setor Educacional do Mercosul", Instituto de Relações Internacionais da PUC-Rio, 2008. Disponível em: <http://www.pucrio.br/pibic/relatorio_resumo2008/relatorios/ccs/iri/iri_ gregory_beshara.pdf $>$. Acesso em: $09 \mathrm{dez} 2009$.

BRASIL. Decreto no 6.094, de 24 de abril de 2007. Disponível em < http://www.planalto.gov.br/ccivil_03/_Ato2007-2010/2007/Decreto/D6094.htm>. Acesso em 15 dez 2009.

COSTA, Edimilson. A globalização e o capitalismo contemporâneo. $1^{\text {a }}$ ed. São Paulo: Expressão Popular, 2008.

GADOTTI, Moacir. O Mercosul Educacional e os desafios do século 21. Brasília: Instituto Nacional de Estudos e Pesquisas Educacionais Anísio Teixeira, 2007.

Convocados, uma vez mais: rupturas e desafios do PDE - vol. 1. São Paulo: Instituto Paulo Freire, 2008. 
GRANDI, Jorge. Defict democratico y social em los processos de integración. In: LAREDO, Iris (org.) Estado, mercado y sociedade em el Mercosur: pautas para su viabilización. Vol. 7. Rosario: Universidad Nacional de Rosario, 1999, p. 69-107.

LAMPERT, Ernani. Educação e Mercosul: desafios e perspectivas. In: Revista da Faculdade de Educação. vol.24 n.2. São Paulo Julh/Dez. 1998.

MERCOSUL/RME/ATA No 02/10. Ata da 39 Reunião de Ministros de Educação do Mercosul realizada no Rio de Janeiro em 26 de novembro de 2010. Disponível em < educacion.mec.gub.uy/boletin/RME\%20noviembre\%202010\%20PPTB.pdf>. Acesso em 15 jan 2011.

MERCOSUL EDUCACIONAL. Indicadores educacionais dos países membros do Mercosul e associados 2006. Disponível em:

<http://mercosul.mec.gov.br/asp/Estatistica/sistemas.asp.> Acesso em $10 \mathrm{dez} 2009$.

PLAN DEL SECTOR EDUCATIVO DEL MERCOSUR - 2006 - 2010: metas y acciones. Disponível em: $<$ http://www.sic.inep.gov.br/index.php?option=com_docman\&task= cat_zzview\&gid=27\&Itemid=32\&lang=br-.>Acesso em $10 \mathrm{de} \mathrm{dez} 2009$.

RAIZER, Leandro. Educação para a Integração: Rumo ao Mercosul Educacional. In: Políticas Educativas, Campinas, v.1, n.1, p. 156-169, out. 2007.

STALLIVIERI, Luciane. O Papel das Instituições de Ensino Superior no Processo de Integração do Mercosul. Disponível em:<http://www.ucs.br/ucs/tplCooperacaoCapa/ cooperacao/ assessoria/artigos/integracao_mercosul.pdf>. Acesso em $12 \mathrm{dez} 2009$.

UNESCO. Declaração de Cochabamba. Bolívia: Unesco, 2001. Disponível em: <http://unesdoc.unesco.org/images/0012/001275/127510por.pdf>. Acesso em 10 dez 2009.

VIDAL, Maria Elena S. A integração cultural do Mercosul. Pelotas: Ed. Universitária/UFPel, 1999.

Notas:

\footnotetext{
${ }^{1}$ Doutorando em Educação no Programa de Pós-Graduação em Educação da Universidade Federal de Santa Maria/RS. Integrante do Grupo de Pesquisa em Políticas Públicas e Gestão Educacional - GPPPGE/UFSM. E-mail: oseiasol@yahoo.com.br.
}

Recebido em: $\quad 03 / 03 / 10$ Aprovado em: $\quad 30 / 10 / 10$ 